\title{
Focus effects \\ on quantifier domains in a visual verification task
}

\author{
Barbara Tomaszewicz \\ University of Cologne \\ btomasze@uni-koeln.de
}

\begin{abstract}
In a visual verification study we investigated how syntactic focus affects the interpretation of quantifiers. We compared the effect of syntactic focus on the truth conditions of sentences with the quantificational adverb only and the superlative quantifier most in Polish. In this language, the scopal properties of most as well as the syntactic construction of the sentence final focus allowed us to predict parallel focus association patterns for both quantifiers. We found that, indeed, syntactic focus is able to guide the attention during visual verification. It is known that prosodic focus is immediately integrated during semantic processing, our study is the first to demonstrate that syntactic focus can facilitate the verification of the truth of a sentence, by guiding attention towards the more salient information in the picture, i.e., the set of focus alternatives.
\end{abstract}

Keywords: quantifier domains; most; only; focus association; visual verification task

\section{Context dependency of quantifiers}

\subsection{Domain restriction}

Quantifiers are interpreted with respect to an implicitly restricted domain. Everybody in the sentence in (1) is not understood as referring to all the people in the world, but as referring to some contextually relevant set of people, for instance, a group that met for tea. Determiner quantifiers have an overt domain restrictor, their NP argument ('no cakes' in (1)), but even here the domain is further pragmatically restricted - the domain of no includes only the relevant cakes; the cakes existing outside of the relevant situation are not included. All the various kinds of quantificational expressions: quantificational DPs, quantificational adverbs, floated quantifiers, modal auxiliaries, degree morphology, etc. are subject to pragmatic restrictions (Lewis 1986; Roberts 1995; Rooth 1992; Vallduví 1992; Schwarzschild 1993, among others). This has been modeled by including a "silent" domain restriction variable, $C$, in the logical syntax (Westerståhl 1984; von Fintel 1994; 2004; Stanley \& Szabó 2000; Martí 2003, among 
others). Being a free variable, $C$ can receive its value from the context in different ways: deictically, e.g., if you hear sentence (1) when you arrive for tea, or anaphorically, e.g., when sentence (2) is interpreted in the context of (1).

(1) Everybody ${ }_{C}$ is upset because there are $\operatorname{no}_{C}$ cakes left.

(2) John has eaten them $\operatorname{all}_{C}$.

\subsection{Focus association}

Given the anaphoric nature of the domain variable, in the absence of explicit context, the focus structure of the sentence can provide a clue about the implicit antecedent for $C$ (Rooth 1992; von Fintel 2004). Focus is licensed by a question, explicitly or implicitly present in the context different foci require different antecedent questions, as illustrated by the contrast in (3a,b) (Jackendoff 1972; Selkirk 1984; 1995; Rooth 1985; 1992; Roberts 1996; among others). This means that the location of the focus indicates which question is relevant in the context when the question is not explicit. The same (implicit) context supplies the value for $C$. The example in (4) shows how focus, expressed as intonational prominence, determines the domain of the quantificational adverb only with consequences for the truth conditions of the sentence: in (4a) the alternatives to 'Mary' are excluded, in (4b) the alternatives to 'a cake' are excluded.

(3) Q: Who did Peter buy a cake?

A: a. Peter bought $[\text { MAry }]_{F}$ a cake.

b. ${ }^{~}$ Peter bought Mary [a CAke $]_{F}$.

(4) a. Peter only ${ }_{C}$ bought $[\text { MAry }]_{F}$ a cake.

Reading: 'Peter bought a cake for Mary and for nobody else.'

b. Peter only ${ }_{C}$ bought Mary [a CAke]F.

Reading: 'Peter bought Mary a cake and nothing else.'

The semantic mechanism that matches the domain of a quantifier with the set of alternatives contributed by focus is called focus association. As shown in (4), the truth-conditional contribution of the adverbial only relies on the association with focus (Rooth 1985; 1992; von Fintel 2004; Beaver \& Clark 2008, among others). Similarly, the superlative quantifier most (i.e., the superlative form of the quantifier many) can associate with focus, see (5a,b) (Ross 1964; Jackendoff 1972; Szabolcsi 1986; 2012; Heim 1985; 1999; Farkas \& É. Kiss 2000; Sharvit \& Stateva 2002). With superlative 
expressions, $C$ is called the comparison set because the specification of the truth conditions involves a comparison between the members of this set. In (5a) the comparison is among the set of cakes that different people bought for Mary. In (5b) the set contains the cakes that Peter bought for different people. $^{1}$

(5) a. $[\text { PEter }]_{F}$ bought Mary the most $_{C}$ cakes.

Reading: 'Peter bought Mary more cakes than anyone else bought her.'

b. Peter bought $[\text { MAry }]_{F}$ the most $_{C}$ cakes.

Reading: 'Peter bought Mary more cakes than he bought for anyone else.'

\subsection{Cross-linguistic differences}

However, as first noted in Pancheva \& Tomaszewicz 2012, unlike only in (4b), the superlative most in English cannot associate with a focus inside its DP, e.g., 'cakes' in (6), which would derive a comparison set containing the alternatives to 'cakes'. The reading resulting from most associating with 'cakes' is unavailable in English. ${ }^{2}$ Pancheva and Tomaszewicz (2012)

${ }^{1}$ The superlative degree quantifier - est in adjectives can also associate with focus. Compare (5a,b) and (ia,b) below. Without focus association, the superlative adjective receives the so-called "absolute reading", illustrated in (i.c), where $C$ simply contains the contextually relevant cakes (Ross 1964).

i. $\quad$ a. $[\text { PEter }]_{\mathrm{F}}$ bought Mary the most $_{C}$ expensive cake.

Reading:

'Peter bought Mary a more expensive cake than anyone else bought her.'

b. Peter bought $[\text { MAry }]_{F}$ the most $_{C}$ expensive cake.

Reading:

'Peter bought Mary a more expensive cake than he bought for anyone else.'

c. Peter bought Mary the most $_{C}$ expensive cake.

Reading:

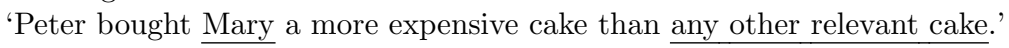

The quantity superlative, most, does not allow the absolute reading (Szabolcsi 1986; Hackl 2000): the sentence Peter bought Mary the most cakes cannot mean that the number of cakes is larger than any other relevant number of cakes. In English most can be used in the most of construction where it receives the "proportional reading". For example, Peter bought Mary most of the cakes means that the proportion of the cakes that Peter bought Mary is larger than the half of all the relevant cakes. Notably, in Polish and in many languages most of has a different lexical form, also based on many but without the superlative morphology, e.g., większość vs. najwięcej in (7), where $n a j$ - is the superlative morpheme (Tomaszewicz 2013b; Pancheva 2015).

${ }^{2}$ Note that the sentence can have a contrastive focus interpretation, with the comparison set specified either as in (5a) or (5b): 'It's cakes and not something else that 
observe that this reading is available in languages where the definite determiner, the, is absent from the DP containing most such as in Polish, cf. (7). With different intonation patterns, the sentence in (7) can have the three interpretations: (5a), (5b), (6).

(6) Peter bought Mary [DP the most $\left._{C}[\mathrm{CAkes}]_{\mathrm{F}}\right]$.

Unavailable reading: 'Peter bought Mary more cakes than anything else he bought her.'

(7) Jan kupił Marii najwięcej $C$ ciastek.

Jan bought Mary most cakes

Available readings: (5a), (5b), (6)

Tomaszewicz (2013a) presents an empirical argument that in Polish the reading in (6) requires focus on 'cakes'. The sentence in (7), where most is in its base position, is three-way ambiguous and prosody disambiguates between the different readings. In (8), however, where most is fronted (via Left Branch Extraction), only one reading obtains, the one paraphrased in (6). While most in (8) is topicalized (optionally, a topic marker 'to' may be present), the noun 'cakes' is obligatorily focused in conformity with the intonational phrasing in Polish (cf. Féry et al. 2007).

(8) Context: Piotr poszedł kupić różne słodycze dla Marii./Piotr went to buy various sweets for Maria.

\begin{tabular}{|c|c|c|c|}
\hline $\begin{array}{l}\left.\left[\text { NajWIEccej}_{1}\right]_{\text {Topic }}(\text { to })\right]_{i} \\
\text { LH }^{*}\end{array}$ & & Marii & $\begin{array}{c}\left.t_{1}[\text { CIAstek }]_{\text {Focus }}\right]_{i} \\
\text { HL* }^{*}\end{array}$ \\
\hline (Topic) & Piotr bough & for-Mary & cakes \\
\hline
\end{tabular}

Reading: 'Peter bought Mary more cakes than anything else he bought her.'

Only in the 'split construction' in Polish behaves in exactly the same way. In (9a) the adjective is topicalized, which makes 'cake' unambigously marked as focus (the sub-extraction from the DP prevents the focus feature F from projecting to a higher constituent). ${ }^{3}$ Only must associate with this

Peter bought Mary more than anyone else did' or 'It's cakes and not something else that Peter bought for Mary more than for anyone else'. An example without an indirect object, makes the contrast between English and Polish more clear - you cannot say 'Look at my plate! I have the most cakes' to mean that you have more cakes than anything else on your plate, but the corresponding sentence in Polish has that meaning (Patrz na mój talerz! Mam najwięcej ciastek).

${ }^{3}$ Nuclear stress is assigned by phonology to every sentence - it is the main sentence stress. In an "all-new" sentence in English nuclear stress is typically assigned to the rightmost content word (e.g., Nuclear Stress Rule of Chomsky \& Halle 1968), but 
focus - the sentence has only one reading. Without the extraction, in (9b), association with 'cake' is difficult, because the focus signaled by the pitch accent can project to the higher constituent, i.e., the DP 'expensive cake'.

(9) Context: Piotr poszedł kupić różne słodycze dla Marii./Piotr went to buy various sweets for Maria.

a. Drogie ${ }_{1}$ pro kupił jej tylko $t_{1}[\text { CIAstko }]_{F}$. expensive bought her only cake

Reading: 'He bought her sweets of which only the cake was expensive.'

b. pro Kupił jej tylko [drogie CIAstko $]_{F}$.

bought her only expensive cake

Reading: 'He bought her only an expensive cake and nothing else.'

The availability of the 'extra' reading for the superlative expressions in Polish (not just for the quantifier most, but also for superlative adjectives, see footnote 1) can be linked to the absence of the definite determiner the, which, as we proposed in Pancheva \& Tomaszewicz (2012) and (Tomaszewicz 2015a;b), in languages like English blocks the degree quantifier - est from scoping outside the superlative DP. In the absence of the, -est can scope into the clause and straightforwardly derive the meaning in (6). As argued in Tomaszewicz (2015b), the reason for this intervention effect is that a morphologically definite superlative DP is necessarily interpreted as semantically definite (see also Coppock \& Beaver 2014). In Tomaszewicz (2015a) I suggested that readings other than (6) can arise in Polish the same way as in English, because the language has no definite determiner and so morphologically unmarked DPs may still be interpreted as definite. But crucially, as I claim in Tomaszewicz (2015b), when -est takes scope in the clause, it obligatorily associates with focus. This approach creates a prediction that in Polish focus association patterns for only, which is standardly assumed to take propositional scope, and for the superlative most should be parallel. The visual verification experiment reported in this paper was designed to test this prediction.

the same location of nuclear stress, indicated by capital letters in (i) below, can be compatible with different sizes of focus-marked elements, indicated by the square brackets (Selkirk 1984; 1995; Gussenhoven 1999, among others).

(i) a. A: What's been happening?

(Selkirk 1996, 554)

B: [Mary bought a book about BATS $]_{F}$.

b. A: What did Mary do?

B: Mary [bought a book about BATS $]_{F}$.

c. A: What did Mary buy a book about?

B: Mary bought a book about $[\text { BATS }]_{F}$. 


\section{The current study}

\subsection{Syntactic focus in Polish}

As discussed in the previous section, in Polish two quantificational operators only and the superlative most can have identical focus association patterns in a particular syntactic construction where focus is obligatorily marked. Crucially, syntactic focus entails that a focus-sensitive quantifier has one interpretation per one sentence string (whereas association with prosodic focus allows for more than one interpretation per one string, as in (4), (5) and (7)). The "split construction" in Polish presented above in (8) and (9a) results in focus on the object noun, 'cake(s)', because it is the sentence final constituent, and as such it receives the nuclear pitch accent (and focus is prosodically marked by the strongest pitch accent in a sentence; see Jackendoff 1972; Selkirk 1984; 1996, among others). In Polish, as in other Slavic languages, with neutral intonation the last constituent in the sentence is marked by the falling accent $\mathrm{HL}^{*}$ and can receive the status of the focus (Dyakonova 2009; Neeleman \& Titov 2009; Bailyn 2012; Jasinskaja 2016). A focus earlier on in the sentence requires non-neutral intonation. Accordingly, right-dislocation of the subject also results in syntactic focus marking with neutral intonation. The quantifiers obligatorily associate with this focus - the sentences in (10) and (11) are unambiguous.

(10) $t_{1}$ NajwięcejC ciastek zjadł $\left[\mathrm{John}_{1}\right]_{\mathrm{F}}$.

most cakes ate John

Reading: 'John ate more cakes than anybody else.'

(11) $t_{1}$ Ciastka zjadł tylko $\left[\mathrm{John}_{1}\right]_{\mathrm{F}}$.

cakes ate only John

Reading: 'Only John ate the cakes.'

We chose Polish for our experiment to test the effects of the sentence final focus position on the domain restriction of most and only with both subjects, as in (10)-(11), and objects, as in (8) and (9a).

Two properties of the sentence final focus construction make it valuable for our investigation. First, both subject and object focus can be tested in a parallel configuration: upon reading the operator, most/only, an expectation for a focus downstream can be created in all of the experimental conditions (whereas with the basic word order, subject focus precedes most but follows only). The second property is the key motivation for this experimental study - syntactic movements like topicalization require contextual licensing. In the absence of prior context, they trigger 
the presupposition that a particular question is currently under discussion (i.e., the reader reconstructs the context appropriate for the given topic). This implicit question, e.g. 'Who ate the cakes?', gets accommodated by the hearer/reader, and thus the set of individuals $x$ such that ' $x$ ate the cakes' becomes salient in the context. This set can then be automatically used as the restriction of the quantifier (von Fintel 1997; 2004). We designed a visual verification task to investigate how the identification of the contents of the restrictor set, $C$, is modulated by the presence/absence of the syntactic focus.

\subsection{Visual verification}

In a visual verification task participants judge the truth/falsity of a sentence against a visual scene; their accuracy and the time to make the judgment are measured. In this task the semantic representation of the sentence makes contact with extralinguistic cognition and the underlying assumption of this methodology since the 1960s is that sentence meanings and perceptual events are encoded in a common representational format (Clark \& Chase 1972; Carpenter \& Just 1975; Gough 1966; Trabasso et al. 1971). Such a format is necessary so that a sentence meaning and a representation of a picture could be compared. Accordingly, the comparison is not based on truth-conditional identity alone, but it specifically involves the identity of representation.

A task where first the sentence is presented and then the picture requires 4 steps: (i) forming a mental representation of the sentence, (ii) forming a mental representation of the picture, (iii) comparing the two representations, (iv) producing a response (Clark \& Chase 1972). Step (iii) is crucial, because the comparison operations might require 'transformations' to make the two representations completely congruent with each other in order to be able to judge if they match. According to Clark's (1969) Principle of Congruence such transformations are more generally required for comprehension, not just in this particular task. For instance, to understand that John killed Harry can be an answer to the question Who died?, you need to match ( $X$ die) against (Harry die) in the proposition represented as (John caused (Harry die)). Only then can you judge that 'Harry died' is fully congruent with the part of the representation of 'John killed Harry'. Similarly, in a visual verification task matching the sentence $A$ is below $B$ against a picture whose mental encoding is ( $B$ above $A$ ) requires a transformation of the representation for a successful match (Clark 1974, 1297). Since we typically inspect a picture in a top-down manner, 
it is more likely that a scene with the letter B at the top and $\mathrm{A}$ at the bottom will be mentally encoded as ( $B$ above $A$ ) rather than ( $A$ below $B$ ). The fact that the representation ( $B$ above $A$ ) requires a transformation to match the sentence $A$ is below $B$ is indicated by the increased reaction times, as measured against a pair that does not require a transformation: the same picture and the sentence $B$ is above $A$. Moreover, when a mismatch/incongruence is detected, e.g., the sentence $B$ is above $A$ with a picture of $A$ on top, the cost of producing the response $N o$ at stage (iv) is further increased. In short, the operations performed at step (iii) can be reflected in both response latencies and accuracy rates (Just \& Carpenter 1971; Clark \& Chase 1972; Clark et al. 1973, among others).

Since our research question is how syntactic focus contributes to the restriction of the domains of the quantificational expressions only and most, the ease/difficulty in the computation of the truth conditions of the sentences should be reflected during the verification against a visual scene, i.e., affecting step (iii) of the task as described above. The truth conditions resulting from focus association (see section 1.2.) are the end result of sentence processing and thus we chose this task rather than simultaneous presentation of a picture and a sentence in a visual world paradigm. In a visual world task, participants hear the sentence as they inspect the visual scene and their eye movements are recorded. This makes it an excellent tool for the investigation of incremental processing, and, in fact, prosodic focus has been shown to trigger anticipatory eye movements when the display supports a contrastive interpretation (e.g., hearing First hang the green ball. Now hang the BLUE..., participants would look at the blue ball before they heard the noun ball; see Ito \& Speer 2008; Weber et al. 2006; Sekerina \& Trueswell 2012). The finding that prosodic focus is immediately integrated into the semantic representation during incremental processing has also been shown for sentences with only (Mulders \& Szendrôi 2016; see also Stolterfoht et al. 2007 and Dimitrova et al. 2010 for evidence from ERPs) and most (Tomaszewicz \& Pancheva 2016).

These results provide us with an important background for the current study: prosodic cues to focus are processed immediately, so we know that focus effects on the truth conditions can be detected immediately (Mulders \& Szendrôi 2016). Our experiment is the first, to our knowledge, to investigate whether syntactic focus, in the absence of any prosodic information (i.e., with written sentences), has an effect on the computation of the truth conditions during online processing. Our main interest is the output of the processes of semantic composition, and the role of those processes (e.g., presence/absence of syntactic focus) in the comparison at stage (iii) of the 
verification process as outlined above. (Unlike in a typical visual world experiment, we are not, at this point, interested in the integration of the semantic and visual information during simultaneous presentation.) In the next section, we present our materials and the design that allowed us to directly compare a sentence with only and a sentence with most against an identical display, in order to compare how association with focus contributes to the truth conditions with each operator.

\subsection{Materials and predictions}

\subsubsection{Materials}

In section 1.3. we showed that in Polish it is possible to compare how the quantificational domains of the two operators only and most get restricted through association with the focus on the object NP. (To recap: due to the fact that Polish has no definite determiner, both only and most can associate with the focus on the object NP, while in a language like English most cannot do so.) Then, in section 2.1. we showed that focus in Polish can be syntactically marked, i.e., when the focused constituent is right-dislocated to the sentence final position.

Most and only must associate with the syntactic focus, and hence only one interpretation is available for a given string (recall that with prosodic focus the same string can have different readings depending on the location of that focus). We also pointed out that the sentence final focus position allows a parallel configuration for both object focus and subject focus, such that the operator precedes the focus. The goal of the experiment is to determine how object focus vs. subject focus in the sentence final position interact with the identification of the contents of the restrictor of most vs. only.

In order to compare the interpretation of sentences with most and those with only with respect to the same set $C$ in a visual scene, we need to use only together with negation. Consider how both (12) and (13) are true in the situation in Figure 1. In both cases, due to subject focus, the set $C$ contains the alternatives to the piglet: the two other animals. In order to verify both sentences, you must check each animal and the cucumber row - both sentences are true with respect to this picture. Without negation, 'Only the piglet ate cucumbers' is false in this picture. The two sentences with object focus, (14)-(15), are true with respect to the situation in Figure 2. Note how in this situation sentence (12) is not true the piglet ate more cucumbers than anything else, but he did not eat more 
cucumbers than the rabbit. Here, by responding 'yes' to the sentence in (14) participants had to confirm that they correctly interpreted the effect of Left Branch Extraction on the interpretation of most.

(12) $t_{1}$ Najwięcej ogórków zjadł [prosiaczek $]_{\mathrm{F}}$. most cucumbers ate piglet MOST - SUBJECT FOCUS Right Dislocation 'The piglet ate more cucumbers than anybody else.'

(13) $t_{1}$ Ogórki zjadł nie tylko $\left[\text { prosiaczek }_{1}\right]_{\mathrm{F}}$. cucumbers ate not only piglet

ONLY - SUBJECT FOCUS Right Dislocation 'Not only the piglet ate cucumbers.'

(14) Najwięcej ${ }_{1}$ prosiaczek zjadł [DP $\left.t_{1}[\text { ogórków }]_{F}\right]$. MOST - OBJECT FOCUS most piglet ate cucumbers

Left Branch Extraction 'The piglet ate more cucumbers than other veggies.'

(15) Prosiaczek zjadł nie tylko [ogórki $]_{F}$. piglet ate not only cucumbers ONLY - OBJECT FOCUS Basic Word Order 'The piglet ate not only cucumbers.'
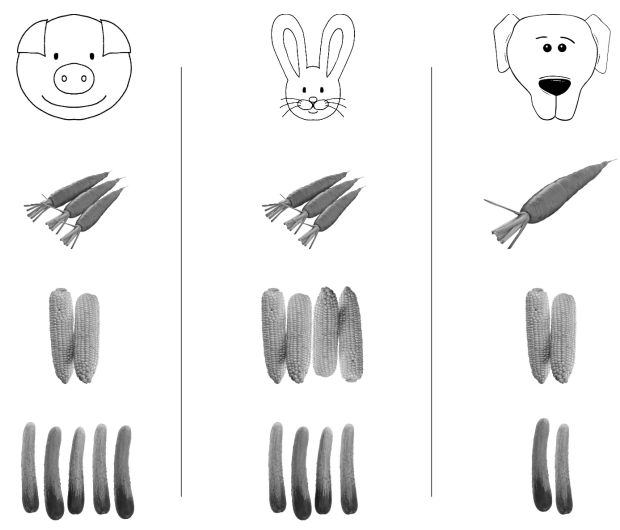

Figure 1: MOST/ONLY - SUBJECT FOCUS

Since the sets of alternatives are the same in the two focus conditions (other animals in the subject focus condition, other vegetables in the object focus condition), the identification of those alternatives should proceed exactly in parallel with both most and only, with a single difference: most additionally requires the estimation of the number of other vegetables (those that other animals ate with subject focus, and those that the piglet ate with object 


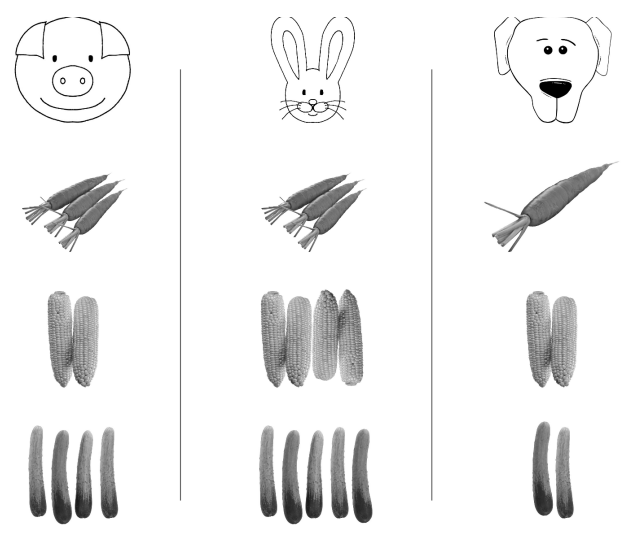

Figure 2: MOST/ONLY - OBJECT FOCUS

focus) (Tomaszewicz 2013a). We formulated our predictions assuming that this difference results in a higher processing cost for the verification of sentences with most than with only.

We hypothesized that the evidence for the facilitatory role of the syntactic focus in the identification of the domain of the operators (i.e., in the processing of focus association) would come from faster/more accurate responses in the conditions with overt syntactic movement, because in those cases focus cannot project and thus F-marking is unambiguous. As discussed in section 2.1., in (12) and (13) the focused subjects are right dislocated; this movement unambiguously identifies the subject as the focus of the sentence. With Left Branch Extraction in (14) the object NP is the unambiguous focus. In (15), however, the basic word order allows for the interpretation where the object NP is a narrow focus, F1 in (16), but the $\mathrm{F}$ feature can also project up to the whole clause, F4 in (16).

(16) $(=(15))\left[_{\mathrm{CP}} \text { Prosiaczek }\left[\mathrm{VP} \text { zjadł }\left[_{\mathrm{DP}} \text { nie tylko }[\mathrm{NP} \text { ogórki. }]_{\mathrm{F} 1}\right]_{\mathrm{F} 2}\right]_{\mathrm{F} 3}\right]_{\mathrm{F} 4}$ piglet ate not only cucumber

'The piglet ate not only cucumbers.'

The following piece of data illustrates that with the basic word order, only is able to associate with VP focus that is not its syntactic associate, but the same is not possible with right-dislocated subjects. The question in (17) licenses wide focus and the answer (a) receives the interpretation where only associates with the whole VP and not the PP 'for a walk'. The position of only does not mark syntactic focus. In fact, (17a) has the same interpretation as (17b), where only is in the clause initial position. 
In (18a) only also takes wide scope - the exclusion concerns propositional alternatives as indicated by the paraphrase (note that this is not possible in English where sentence-initial only does not scope over the whole clause; this is possible in German (Büring \& Hartmann 2001)). However, in (18b) only must associate with narrow focus on the right-dislocated subject. Accordingly, (18b) is an infelicitous answer to the wide-focus question in contrast to (17a).

(17) Q: Czy robiliście dziś coś ciekawego?

'Did you do anything interesting today?'

A: a. Nie. Poszliśmy tylko na spacer.

no went.3PL only for walk

'No. We only went for a walk.'

b. Nie. Tylko poszliśmy na spacer.

no only went.3PL for walk

'No. We only went for a walk.'

(18) Q: Czy robiliście dziś coś ciekawego?

'Did you do anything interesting today?'

A: a. Nie. Tylko dziadek poszedł na spacer.

no only grandpa went.3sG for walk

'No. Nothing else happened except that grandpa went for a walk.'

b. "Nie. Na spacer poszedł tylko dziadek.

no for walk went.3SG only grandpa

'No. It's only grandpa who went for a walk.'

What this means for the present study is that ONLY - OBJECT FOCUS is the only condition where the sentence final NP can but does not have to be interpreted as a syntactic focus, that is, focus marking is less salient than in sentences with syntactic movement.

\subsubsection{Procedure}

Participants $(n=34)$ first read the stimulus sentence presented in the center of the screen, and then pressed a button for the picture to be displayed (in full colour). They judged whether the picture matched the sentence by pressing a "yes" or "no" button on the button box. The picture was displayed until the yes-no response, for up to 10s. Accuracy was encouraged by an auditory signal in case of a wrong response. Participants saw 6 practice trials followed by 96 experimental trials in four blocks. On 48 trials they saw the test sentence-picture pairs in the four conditions: MOST 
- SUBJECT FOCUS, ONLY - SUBJECT FOCUS, MOST - OBJECT FOCUS, ONLY - OBJECT FOCUS, see (12)-(15). There were 24 stimuli for each condition, distributed across four lists in a Latin Square design. On the other half of the trials the participants saw filler sentence-picture pairs with quantifiers kilka 'a few', pare 'a couple', dużo 'many' and numerals 'three', 'four', 'five', 'six'. None of the filler sentences contained syntactic movement, thus they were all parallel to the ONLY - OBJECT FOCUS condition.

Half of all trials required a yes- and half required a no-response. The test items with no-responses could not be matched with the same screen, and therefore could not be directly compared (see Appendix). Since a "no" judgment will require a different verification process than a "yes" judgment, our experimental design had three factors, each with two levels: operator (MOST, ONLY), focus type (SUBJECT, OBJECT), and congruence of the sentence-picture pairs (congruent/yes-judgment, incongruent/nojudgment). During the inspection of the picture, the participants' eyemovements were recorded, but the eye-tracking data is not reported in this paper, because the predictions for the RTs and accuracy rates can be independently formulated.

\subsubsection{Predictions}

As discussed in the previous section, in a visual verification task the yesno decision is preceded by a series of comparison operations between the mental representation of the sentence and the mental representation of the visual scene. Straightforwardly, a larger number of such operations corresponds to longer RTs. If longer RTs are observed together with a higher number of errors, we can conclude that the matching process is difficult and unsuccessful. If, on the other hand, longer RTs occur together with no difference in accuracy rates, we see that the extra comparison operations enable a successful match. Accordingly, response latencies are the main indicator of the number of comparison operations required to identify the set of alternatives in the picture (i.e., the other animals or the other vegetables in Figures 1-2), thus we formulate our predictions in terms of differences in the reaction times.

Our theoretical hypothesis, that syntactic focus facilitates the processing of focus association, does not carry over to a single statistical hypothesis. The $2 \times 2 \times 2$ design, crossing Operator Type, Focus Type and Congruence, allows for three possible outcomes with statistically significant effects, but only the third option described below could provide evidence in support of our hypothesis. (i) The first option is that the syntactic focus manipulation has no effect whatsoever, the only difference is due to the 
number estimation required for the verification of most (main effect of Operator Type). The hypothetical results in this case might look like in the graph in Figure 3i: the predicted RTs for the responses for sentences with most are higher than those for sentences with only; the RTs are no different for object and subject focus. (ii) The second possibility is that the RTs are significantly affected by the overall syntactic complexity of the sentence, rather than the focus manipulation. This is illustrated in Figure 3ii: the RTs for most are slower due to number estimation (just like in Figure 3i), but, additionally, because the MOST - OBJECT FOCUS condition involves Left Branch Extraction (i.e., is the most complex syntactically), the RTs are significantly slower than in the MOST - SUBJECT FOCUS condition, i.e., there is an interaction. Since ONLY - OBJECT FOCUS condition has the basic word order (i.e., is the least complex), it receives significantly faster RTs than the ONLY - SUBJECT FOCUS condition, where the subject is right dislocated.
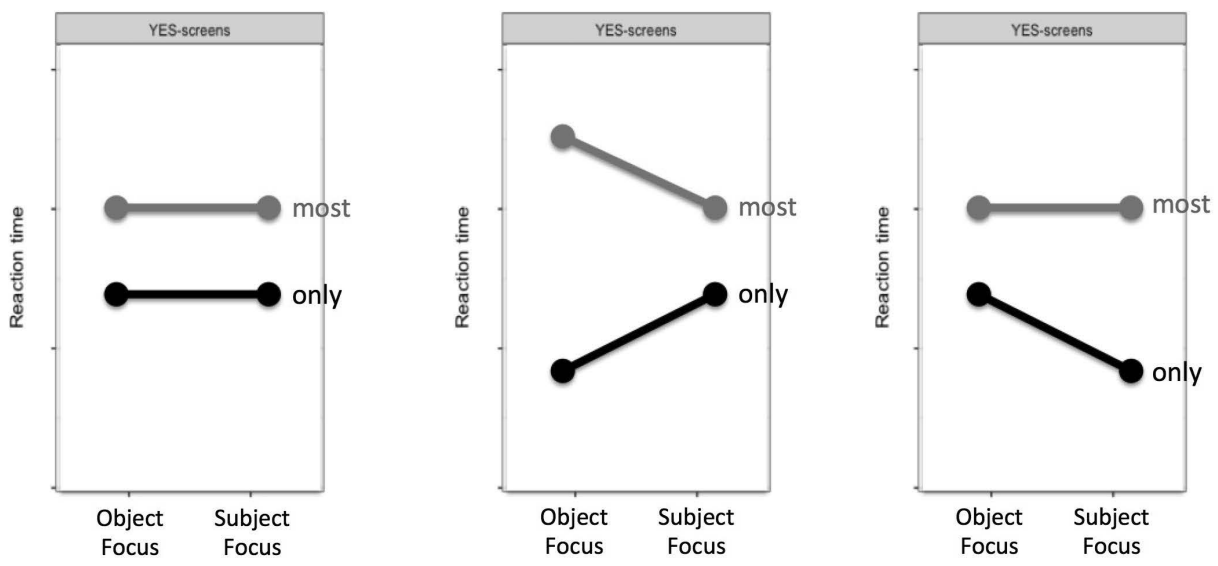

Figure 3: Predictions (i)-(iii)

The hypothetical outcomes (i)-(ii) provide no evidence for the role of syntactic focus in the processing of focus association. Such evidence would be provided by the hypothetical outcome (iii) depicted in Figure 3iii. Here the RTs for most are no different for the subject and object focus conditions, because both contain syntactic focus. Crucially, the RTs for only show faster RTs for the right-dislocated subject focus, and significantly slower RTs for the object focus sentences with the basic word order. This hypothetical result for only is exactly the opposite from what is predicted in option (ii), Figure 3ii. Hypotheses (ii) and (iii) differ in the direction of the 
interaction. If non-canonical word order is harder to process than the basic word order, ONLY - OBJECT FOCUS will receive lower RTs (Figure 3ii). If, on the other hand, the right dislocation of the subject unambiguously marks it as the focus, it should facilitate the identification of the restrictor set, and the ONLY - SUBJECT FOCUS condition should receive lower RTs (Figure 3iii).

\subsection{Results}

We fitted a mixed-effects regression model of the log-transformed RTs and a mixed effects logistic regression model of the (binary) yes/no variable in $\mathrm{R}$ version 3.4.1 ( $\mathrm{R}$ Development Core Team 2017) using the lme4 package version 1.1-13 (Bates et al. 2015). Predictor variables included Operator Type (most, ONLY), Focus Type (subJect, oBJect), Congruence (congruent/yes-judgment, incongruent/no-judgment) and their interactions. We used ANOVA-style sum-coded contrasts to test for main effects in the presence of an interaction. We included random intercepts and slopes for participants and items whenever supported by the data (Barr et al. 2013). In cases of convergence failures or of zero/perfectly correlated random terms with very low standard deviations, the random effects structure was simplified following Baayen et al. (2008). The $p$-values were obtained using the Satterthwaite approximation implemented in the lmerTest package (Kuznetsova et al. 2016).

The log-transformed RTs for the yes- and no-responses are presented in Figure 4 (error bars represent standard errors). We find a main effect of the type of operator $(\beta=0.0586, \mathrm{SE}=0.025, t=2.371, p=.021)$, which we expected to be driven by the fact that most requires the estimation of the numbers of, e.g., vegetables in Figures 1-2. All of the interactions are significant: Operator Type $*$ Focus Type $(\beta=-0.097, \mathrm{SE}=$ $0.041, t=-2.394, p=0.018)$, Operator Type $*$ Congruence $(\beta=$ $0.139, \mathrm{SE}=0.041, t=3.437, p=0.0007)$, Focus Type $*$ Congruence $(\beta=-0.197, \mathrm{SE}=0.041, t=-4.852, p<0.0001)$, Operator Type $*$ Focus Type $*$ Congruence $(\beta=0.246, \mathrm{SE}=0.081, t=3.04, p=0.0027)$. The interactions reflect the difference in the RT patterns for yes- and no-conditions. As can be seen in the graph, with congruent pairs (yesjudgments) both operators receive significantly faster RTs with subject focus than object focus, but with incongruent pairs (no-judgments) most is unaffected by focus type, while only is significantly slower with subject 
focus. As pointed out in the previous section, only with yes-judgments were the two operators presented with the exact same display. ${ }^{4}$

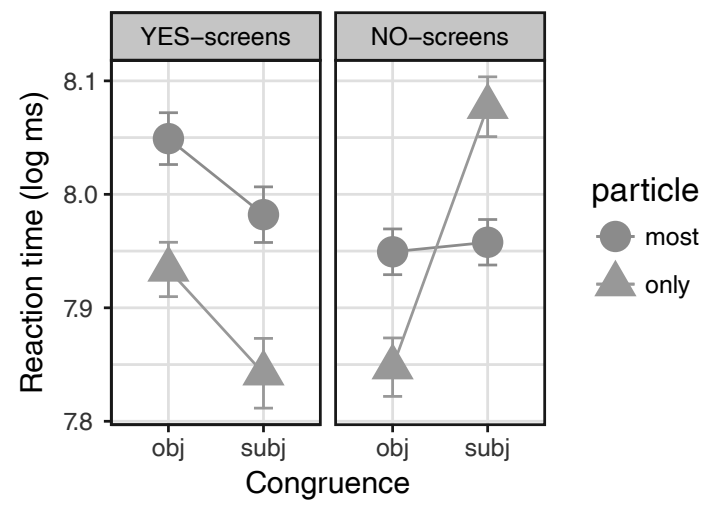

Figure 4: Reaction times

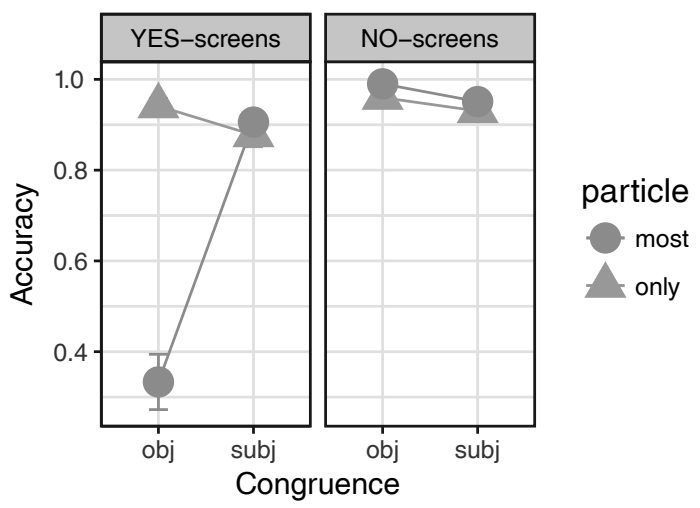

Figure 5: Accuracy

${ }^{4}$ The differences between the no-displays (see Appendix) appear to fit with the RT results. In the display for the ONLY - OBJECT FOCUS condition, the piglet's column filled with just potatoes is easily noticeable and hence the truth of the sentence 'The piglet ate not only potatoes' can easily be rejected. In the picture for the ONLY SUBJECT FOCUS condition, you have 4, and not 3, kinds of vegetables, which makes the scene more complex. In the two MOST conditions the display was the same, and indeed we see no differences in RTs. 
With yes-responses, the RT results for most appear to be compatible with hypothesis (ii), and the results for only with hypothesis (iii). Hypothesis (iii) was that if syntactic focus does facilitate the identification of the restrictor set, then the RTs with only should be faster with subject focus than with object focus, and this is indeed what we find. The fact that with only the dislocated subject focus facilitates verification suggests that syntactic focus marking has a processing advantage over complexity.

However, the hypothesis (iii) for most was that there should be no differences between the two focus types because both are syntactically derived through movement. Instead, we find evidence that object focus with most, derived by Left Branch Extraction takes longer to verify than subject focus, derived by Right Dislocation. This is compatible with hypothesis (ii) that syntactic complexity affects the ease/difficulty for verification.

The accuracy rates reveal that the RT patterns for most indeed result from the increase of syntactic complexity: Left Branch Extraction > Right Dislocation. As can be seen in Figure 5, the increased RTs in the MOST - OBJECT FOCUS condition are simply due to wrong responses. While accuracy is high in all the other conditions, $87-99 \%$ correct, in the MOST OBJECT FOCUS condition it is as low as 33\%. This shows that participants failed to parse the Left Branch Extraction structure as topicalization with sentence final narrow focus (as shown in (8) in section 1.3.). In fact, during the post-experiment debriefing many participants were surprised about their errors with most stimuli (recall that wrong responses had an auditory signal to encourage them to pay more attention); they did not notice that there were two types of sentences with most but when the experimenter pronounced the LBE sentence with the intonation indicated in (8), all of the participants agreed that there was just one interpretation and that they had missed it. This result indicates that when syntactically complex sentences are associated with special intonation (recall the that the LBE construction was more complex than all the other types of sentences, including fillers), the task should make sure participants read the sentences more carefully, e.g., via phrase-by-phrase presentation, which has been proven successful at detecting differences in implicit prosody (Stolterfoht et al. 2007; Pratt 2015). In fact, 7 out of the 34 participants had accuracy above chance (in fact, above $83 \%$ ) in the MOST - OBJECT FOCUS condition and had no trouble parsing those sentences in the intended way. Their RT results are presented in Figure 6. Indeed, these RT results, both for only and most, are in line with our hypothesis (iii). ${ }^{5}$

${ }^{5}$ The $p$-values for the subgroup analysis are not included as they are not meaningful (see, e.g., Gelman \& Loken 2013). 


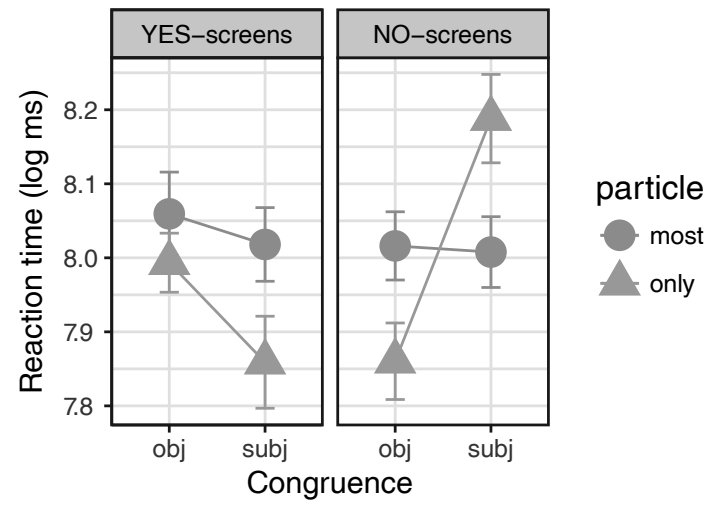

Figure 6: Reaction times of the participants with high accuracy on the MOST OBJECT FOCUS condition

\section{Discussion and conclusions}

Our visual verification experiment was designed to test how in Polish sentences with the quantificational adverb only and the quantifier most are verified against a visual scene. Both operators are focus sensitive, i.e., their truth-conditional contribution depends on the focus structure of the sentence. We used a particular reading of the sentences with most in Polish, in which the superlative operator must scope at the sentential level (Pancheva \& Tomaszewicz 2012; Tomaszewicz 2015b), exactly parallel to only, which is standardly assumed to take propositional scope. Since it is known that prosodic focus is immediately integrated during incremental processing (Ito \& Speer 2008; Weber et al. 2006; Sekerina \& Trueswell 2012), with truth-conditional effects for the interpretation of only (Mulders \& Szendrói 2016), our goal was to investigate the role of syntactic focus in silent reading. In Polish syntactic focus can be the result of Right Dislocation or Left Branch Extraction, and we tested whether the presence of such syntactic movement signals to the reader what the focus alternative set is.

On each trial, participants first read the test sentence, then saw a picture and judged whether the sentence was true/false with respect to that picture. As discussed in section 2.2., the visual verification paradigm is based on the assumption that both the mental representation of the sentence and of the picture must be in a common format in order for us to judge whether the two representations match or not (Clark \& Chase 1972; among others). If the mental representations are not identical, during 
their comparison the mind performs transformation operations to find the closest match. The closer the match between the two representations, the fewer adjustments are needed, making the yes-no judgment easier and thus faster. We hypothesized (hypothesis (iii) in Section 2.3.3.) that if syntactic focus is a salient cue to domain restriction, during the picture verification phase, participants would be biased to obtain a matching mental representation of the visual scene, which would facilitate the yes-no judgment. This prediction was partially met: we found the facilitation for the sentences with only, but not for sentences with most.

We found that the judgment in the ONLY - SUBJECT FOCUS condition, (19), received significantly faster reaction times than the ONLY - OBJECT FOCUS condition, (20).

$$
\begin{gathered}
(=(13)) t_{1} \text { Ogórki zjadł nie tylko }\left[\text { prosiaczek }_{1}\right]_{\mathrm{F}} . \\
\text { cucumbers ate not only piglet } \\
\text { 'Not only the piglet ate cucumbers.' }
\end{gathered}
$$

ONLY - SUBJECT FOCUS Right Dislocation

$$
\begin{gathered}
(=(15)) \text { Prosiaczek zjadł nie tylko [ogórki }]_{F} . \\
\text { piglet ate not only cucumbers } \\
\text { 'The piglet ate not only cucumbers.' }
\end{gathered}
$$

ONLY - OBJECT FOCUS Basic Word Order

The ONLY - SUBJECT FOCUS condition is syntactically more complex, but the right dislocated subject unambiguously identifies that the set of alternatives contains the other animals in the display (Figure 1). In the ONLY - OBJECT FOCUS condition the NP 'cucumbers' is also interpreted as focus, but the structure of the sentence (basic word order) allows the F-marking to project to higher constituents, i.e., the F-marking is ambiguous (though the sentence interpretation is not). All of our filler sentences had basic word order (and contained quantifiers a few, a couple, many and numerals), therefore the presence of syntactic movement was a more salient cue to the focus interpretation than the just the presence of only in the ONLY - OBJECT FOCUS condition. In experiments where sentences with and without only were compared, facilitation occurred due to the presence of only (Stolterfoht et al. 2007; Carlson 2013; Tomaszewicz \& Pancheva 2016). Here, syntactic focus served as the additional cue, and we found that its effect was significant.

Could this result be explained by the properties of the visual scene instead of the syntactic focus? ${ }^{6}$ It does not seem so. In both ONLY condi-

${ }^{6}$ I thank the audience of the General Linguistics Colloquium Series in Tübingen for raising this point. 
tions, during the visual inspection of the scene, you first need to identify the right animal, the piglet. Secondly, for the SUBJECT FOCUs sentences, you need to find the row with the cucumbers and then check if other animals' columns also contain cucumbers. For the OBJECT FOCUS sentences, you need to check if the piglet's column has cucumbers and other things, i.e., it is not only filled with cucumbers (as on the no-response screens, see Appendix). It seems that if the properties of the visual scenes were driving the effects, then the verification of sentences with OBJECT FOCUS should be easier. The fact that it is not suggests that (a) syntactic focus marking has a processing advantage over syntactic complexity, and (b) syntactic focus guides the attention towards the more salient information in the picture, i.e., the set of focus alternatives.

Syntactic focus with most also appeared to facilitate the identification of the restrictor set, but only in a subgroup of participants, namely those who appropriately parsed the Left Branch Extraction construction where the remnant NP is the focus, as in (22). Those participants who failed to parse it correctly did not assign the correct truth conditions to the sentence and incorrectly replied 'no' on the 'yes' screens (Figure 5). That is, they misread sentence (22) as (21).

(21) $(=(12)) t_{1}$ Najwięcej ogórków zjadł $\left[\text { prosiaczek }_{1}\right]_{\mathrm{F}}$. most cucumbers ate piglet 'The piglet ate more cucumbers than anybody else.'
MOST - SUBJECT FOCUS Right Dislocation
$(=(14))$ Najwiecej 1 prosiaczek zjadł [DP $\left.t_{1}[\text { ogórków }]_{F}\right] . \quad$ MOST - OBJECT FOCUS most piglet ate cucumbers Left Branch Extraction 'The piglet ate more cucumbers than other veggies.'

Out of the 34 participants only 7 gave the correct judgments. This result, however, is not incompatible with the claim that most obligatorily associates with focus when it takes propositional scope (Tomaszewicz 2015a;b). If most in (22) was able to associate with 'piglet', the RTs should be no different than for (21). The increased RTs (Figure 4) show that participants did detect some anomaly with (22), which was absent with (21). Additionally, their incorrect "no" responses in this condition took longer than the 'no' responses with most on the 'no' screens, as can be seen in Figure 4. This indicates that the judgments in the MOST - OBJECT FOCUS condition were particularly difficult - syntactic complexity of Left Branch Extraction interfered with both sentence interpretation and picture verification. This result shows that our task failed to ensure that participants read the sentences carefully. As we saw in Figure 6, the participants who 
did correctly interpret the LBE sentences took the same amount of time for picture verification in the MOST - OBJECT FOCUS condition as in the MOST - SUBJECT FOCUS condition. In this subgroup, syntactic focus seems to facilitate in both cases.

The results of our visual verification experiment show that the mechanism of focus association that has been proposed for the derivation of focus effects on the interpretation of quantifiers (Rooth 1992; von Fintel 2004; Beaver \& Clark 2008) affects the process of sentence-picture matching during the verification of the truth value. The mental representation of a sentence containing most/only and syntactic focus includes the representation of a set of alternatives, and during the visual inspection of the picture the identification of that set is facilitated. While a high level of syntactic complexity interfered with both sentence interpretation and picture verification (in the case of Left Branch Extraction), crucially, syntactic focus derived by Right Dislocation made picture verification easier than with the less complex structure where F-marking was ambiguous. This study is the first to show that in a reading task, syntactic focus can guide attention towards the more salient information in the picture, i.e., the set of focus alternatives.

\section{Acknowledgements}

I would like to thank Andreas Brocher for his involvement in the design of the study and the programming in Experiment Builder, Yaman Özakın for creating the grids with images and Hanna Kędzierska for help with the recording. I am also grateful for helpful comments and discussion to Roumi Pancheva, Petra B. Schumacher, Hanna Weiland-Breckle, the audiences of the General Linguistics Colloquium Series in Tübingen organized by Michael Franke and of the kick-off workshop for the Cognitive Semantics of Quantities project run by Jakub Szymanik at the University of Amsterdam. This research was funded by the OPUS 5 HS2 grant (DEC-2013/09/B/HS2/02763) from the Polish National Science Center $(\mathrm{NCN})$. 


\section{Appendix}
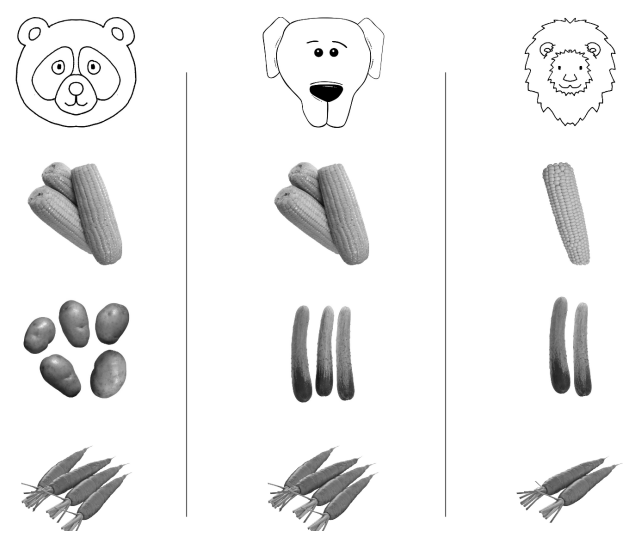

Figure 7: Ziemniaki zjadt nie tylko miś. 'Not only the bear ate potatoes.'
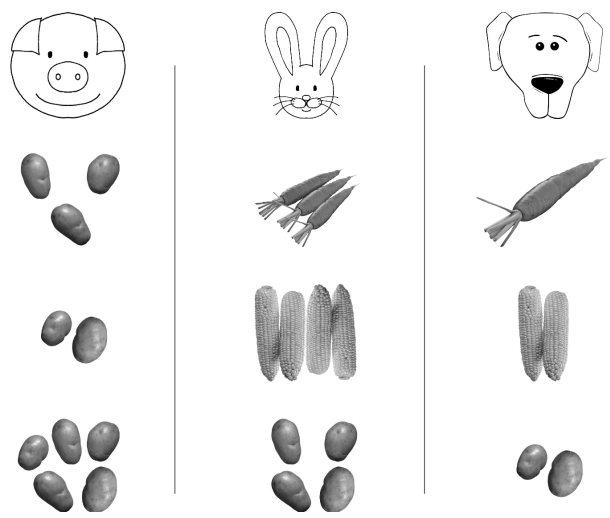

Figure 8: Prosiaczek zjadt nie tylko ziemniaki. 'The piglet ate not only potatoes.' 


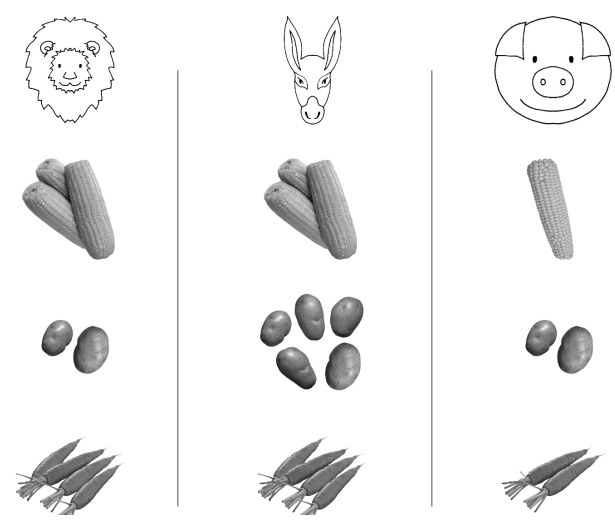

Figure 9: Najwięcej lew zjadt ziemniaków. 'The lion ate more potatoes than anything.'; Najwięcej ziemniaków zjadt lew. 'The lion ate more potatoes than anyone.'

\section{References}

Baayen, R. Harald, Doug J. Davidson and Douglas M. Bates. 2008. Mixed-effects modeling with crossed random effects for subjects and items. Journal of Memory and Language 59. 390-412.

Bailyn, John F. 2012. The syntax of Russian. Cambridge: Cambridge University Press.

Barr, Dale J., Roger Levy, Christoph Scheepers and Harry J. Tily. 2013. Random effects structure for confirmatory hypothesis testing: Keep it maximal. Journal of Memory and Language 68. 255-278.

Bates, Douglas, Martin Maechler, Ben Bolker and Steve Walker. 2015. Fitting linear mixedeffects models using lme4. Journal of Statistical Software 67. 1-48.

Beaver, David and Brady Clark. 2008. Sense and sensitivity. Malden, MA \& Oxford: Blackwell.

Büring, Daniel and Katharina Hartmann. 2001. The syntax and semantics of focus-sensitive particles in German. Natural Language \& Linguistic Theory 19. 229-281.

Carlson, Katy. 2013. The role of only in contrasts in and out of context. Discourse Processes 50. 249-275.

Carpenter, Patricia A. and Marcel A. Just. 1975. Sentence comprehension: A psycholinguistic processing model of verification. Psychological Review 1975. 45-73.

Chomsky, Noam and Morris Halle. 1968. The sound pattern of English. New York: Harper \& Row.

Clark, Herbert H. 1969. Linguistic processes in deductive reasoning. Psychological Review 76. 387-404.

Clark, Herbert H. 1974. Semantics and comprehension. In T. A. Sebeok (ed.) Current trends in linguistics: Linguistics and adjacent arts and sciences (vol. 12). The Hague: Mouton. 1291-1428. 
Clark, Herbert H., Patricia Ann Carpenter and Marcel Adam Just. 1973. On the meeting of semantics and perception. In W. G. Chase (ed.) Visual information processing. New York: Academic Press. 311-381.

Clark, Herbert H. and W. G. Chase. 1972. On the process of comparing sentences against pictures. Cognitive Psychology 3. 472-517.

Coppock, Elizabeth and David Beaver. 2014. A superlative argument for a minimal theory of definiteness. In T. Snider, S. D'Antonio and M. Weigand (eds.) Proceedings of Semantics and Linguistic Theory (SALT) 24. Ithaca, NY: CLC Publications. 177-198.

Dimitrova, Diana V., Laurie A. Stowe, Gisela Redeker and John C. J. Hoeks. 2010. Focus particles and prosody processing in Dutch: Evidence from ERPs. Speech Prosody 100979. 1-4.

Dyakonova, Marina. 2009. A phase-based approach to russian free word order. Leiden: Netherlands Graduate School of Linguistics.

Farkas, Donka and Katalin É. Kiss. 2000. On the comparative and absolute readings of superlatives. Natural Language \& Linguistic Theory 18. 417-455.

Féry, Caroline, Alla Paslawska and Gisbert Fanselow. 2007. Nominal split constructions in Ukrainian. Journal of Slavic Linguistics 15. 3-48.

Fintel, Kai von. 1994. Restrictions on quantifier domains. Doctoral dissertation. University of Massachusetts at Amherst.

Fintel, Kai von. 2004. A minimal theory of adverbial quantification. In H. Kamp and B. Partee (eds.) Context-dependence in the analysis of linguistic meaning. Amsterdam: Elsevier. 137-175.

Gelman, Andrew and Eric Loken. 2013. The garden of forking paths: Why multiple comparisons can be a problem, even when there is no "fishing expedition" or " $p$-hacking" and the research hypothesis was posited ahead of time. Manuscript. Department of Statistics, Columbia University, New York.

Gough, Philip B. 1966. The verification of sentences: The effects of delay of evidence and sentence length. Journal of Verbal Learning and Verbal Behavior 5. 492-496.

Gussenhoven, Carlos. 1999. On the limits of focus projection in English. In P. Bosch and R. van der Sandt (eds.) Focus: Linguistic, cognitive, and computational perspectives. Cambridge: Cambridge University Press. 43-55.

Hackl, Martin. 2000. Comparative quantifiers. Doctoral dissertation. MIT.

Heim, Irene. 1985. Notes on comparatives and related matters. Ms. University of Texas.

Heim, Irene. 1999. Notes on superlatives. Ms. MIT.

Ito, Kiwako and Shari R. Speer. 2008. Anticipatory effects of intonation: Eye movements during instructed visual search. Journal of Memory and Language 58. 541-573.

Jackendoff, Ray. 1972. Semantic interpretation in generative grammar. Cambridge, MA: MIT Press.

Jasinskaja, Katja. 2016. Information structure in Slavic. In C. Féry and S. Ishihara (eds.) The Oxford handbook of information structure. Oxford: Oxford University Press. 709-732.

Just, Marcel A. and Patricia A. Carpenter. 1971. Comprehension of negation with quantification. Journal of Verbal Learning and Verbal Behavior 10. 244-253.

Kuznetsova, Alexandra, Per Bruun Brockhoff and Rune Haubo Bojesen Christensen. 2016. lmerTest: Tests in Linear Mixed Effects Models. R package version 2.0-32. 
Lewis, David. 1986. On the plurality of worlds. Oxford: Blackwell.

Martí, Luisa. 2003. Contextual variables. Doctoral dissertation. University of Connecticut.

Mulders, Iris and Kriszta Szendrői. 2016. Early association of prosodic focus with "alleen" 'only': Evidence from eye movements in the visual-world paradigm. Frontiers in Psychology 7 .

Neeleman, Ad and Elena Titov. 2009. Focus, contrast, and stress in Russian. Linguistic Inquiry 40. 514-524.

Pancheva, Roumyana. 2015. Quantity superlatives: The view from Slavic and its crosslinguistic implications. In H. Aparicio, G. Flinn, K. Franich, J. Pietraszko and T. Vardomskaya (eds.) Proceedings of the Forty-ninth Annual Meeting of the Chicago Linguistic Society (CLS 49). Chicago: Chicago Linguistic Society.

Pancheva, Roumyana and Barbara Tomaszewicz. 2012. Cross-linguistic differences in superlative movement out of nominal phrases. In N. Arnett and R. Bennett (eds.) Proceedings of the 30th West Coast Conference on Formal Linguistics. Somerville, MA: Cascadilla Proceedings Project. 292-302.

Pratt, Elizabeth. 2015. Is cue-based memory retrieval "good-enough"?: Agreement, comprehension, and implicit prosody in native and bilingual speakers of English. Doctoral dissertation. City University of New York.

R Development Core Team. 2017. R: A language and environment for statistical computing. Vienna: Foundation for Statistical Computing. http://www.R-project.org

Roberts, Craige. 1995. Domain restriction in dynamic semantics. In E. Bach, E. Jelinek, A. Kratzer and B. H. Partee (eds.) Quantification in natural languages. Dordrecht: Kluwer. 661-700.

Roberts, Craige. 1996. Information structure in discourse: Towards an integrated formal theory of pragmatics. In J. H. Yoon and A. Kathol (eds.) OSU Working Papers in Linguistics 49: Papers in Semantics. Columbus: The Ohio State University. 91-136.

Rooth, Mats. 1985. Association with focus. Doctoral dissertation. University of Massachusetts, Amherst.

Rooth, Mats. 1992. A theory of focus interpretation. Natural Language Semantics 1. $75-116$

Ross, John Robert. 1964. A partial grammar of English superlatives. MA thesis. University of Pennsylvania.

Schwarzschild, Roger. 1993. The contrastiveness of associated foci. Manuscript. Hebrew University of Jerusalem.

Sekerina, Irina A. and John C. Trueswell. 2012. Interactive processing of contrastive expressions by Russian children. First Language 32. 63-87.

Selkirk, Elisabeth O. 1984. Phonology and syntax. The relation between sound and structure. Cambridge, MA: MIT Press.

Selkirk, Elisabeth O. 1995. Sentence prosody: Intonation, stress and phrasing. In J. A. Goldsmith (ed.) The handbook of phonological theory. Cambridge, MA \& Oxford: Blackwell. 550-569.

Sharvit, Yael and Penka Stateva. 2002. Superlative expressions, context, and focus. Linguistics and Philosophy 25. 453-505.

Stanley, Jason and Zoltán G. Szabó. 2000. On quantifier domain restriction. Mind and Language 15. 219-261. 
Stolterfoht, Britta, Angela D. Friederici, Kai Alter and Anita Steube. 2007. Processing focus structure and implicit prosody during reading: Differential ERP effects. Cognition 104. 565-590.

Szabolcsi, Anna. 1986. Comparative superlatives. MIT Working Papers in Linguistics 8. $245-266$.

Szabolcsi, Anna. 2012. Compositionality without word boundaries: (the) more and (the) most. In A. Chereches (ed.) Proceedings of Semantics and Linguistic Theory (SALT) 22. Ithaca, NY: CLC Publications. 1-25.

Tomaszewicz, Barbara. 2013a. Focus association in superlatives and the semantics of "-est". In M. Aloni, M. Franke and F. Roelofsen (eds.) Proceedings of the 19th Amsterdam Colloquium. Amsterdam: University of Amsterdam, Institute for Logic, Language and Computation. 226-233.

Tomaszewicz, Barbara. 2013b. Linguistic and visual cognition: Verifying proportional and superlative "most" in Bulgarian and Polish. Journal of Logic, Language and Information 22. 335-356.

Tomaszewicz, Barbara. 2015a. Relative readings of superlatives: Scope or focus? In S. D'Antonio, M. Moroney and C. R. Little (eds.) Proceedings of the 25th Semantics and Linguistic Theory Conference. Washington, DC: Linguistic Society of America and Cornell Linguistics Circle. 452-470.

Tomaszewicz, Barbara. 2015b. Superlative ambiguities: A comparative perspective. Doctoral dissertation. University of Southern California.

Tomaszewicz, Barbara and Roumyana Pancheva. 2016. Obligatory and optional focus association in sentence processing. In F. Salfner and U. Sauerland (eds.) Pre-proceedings of Trends in Experimental Pragmatics. Berlin: XPRAG.de. 153-161.

Trabasso, Tom, Howard Rollins and Edward Shaughnessy. 1971. Storage and verification stages in processing concepts. Cognitive Psychology 2. 239-289.

Vallduví, Enric. 1992. The information component. Doctoral dissertation. University of Pennsylvania.

Weber, Andrea, Martine Grice and Matthew W. Crocker. 2006. The role of prosody in the interpretation of structural ambiguities: A study of anticipatory eye movements. Cognition 99. B63-B72.

Westerståhl, Dag. 1984. Determiners and context sets. In J. van Benthem and A. ter Meulen (eds.) Generalized quantifiers in natural language. Dordrecht: Foris. 45-71. 